\title{
Maximum Power Point tracking for a stand-alone photovoltaic system using Artificial Neural Network
}

\author{
Nabila Ghedhab ${ }^{1, *}$, Fatiha Youcefettoumi ${ }^{1}$, Abdelhamid Loukriz $^{2}$ and Allaeddine Jouama ${ }^{1}$ \\ ${ }^{1}$ Department of Electronic Engineering University of Science and Technology Houari Boumedien Algiers, Algeria \\ ${ }^{2}$ Department of Electrical Engineering High school of Polytechnic ENP Algiers, Algeria
}

\begin{abstract}
This paper presents an intelligent method to extract the maximum power from the photovoltaic panel using artificial neural network (ANN). The inputs data required for training the ANN controller are obtained from real weather conditions and the desired output is obtained from perturb and observe (P\&O) method. The proposed model is capable to improve the dynamic response and steady-state performance of the system, provides an accurate identification of the optimal operating point and an accurate estimation of the maximum power from the photovoltaic panels. The proposed ANN model is compared with conventional P\&O model and shown that ANN controller could increase the power output by approximately $20 \%$. The system is simulated and studied using MATLAB software.
\end{abstract}

\section{Introduction}

Algeria has created a green momentum by launching an ambitious program to develop renewable energy resource by promoting the research and development mainly for solar energy area [1]. For this purpose and in case of photovoltaic power supply all efforts are gathered to increase the energy efficiency. The output power from the photovoltaic (PV) panel depends on weather conditions. Therefore, a continuous identification of the optimal operating point is required to achieve the maximum output efficiency. In this context our interest is focused on the use of maximum power point tracking (MPPT) techniques, their prime purpose is to extract the maximum possible energy from the source and to deliver it to the load. A variety of MPPT methods have been developed in the literature [24], some of them are simple and widely used like perturb and observe (P\&O) method [5-6], Incremental Conductance (IC) [7-8]. But some others are more complexes and cost effective, that include artificial neural network (ANN) [9-13], fuzzy logic methods [1415], and genetic algorithms [16].

Since PV systems are non linear, ANNs are highly recommended techniques regardless of their initial cost compared to the increase in power and stability that can offer. In this paper MPPT based ANN controller will be proposed, the performance of this technique will be validated by simulation in Matlab/simulink and compared to MPPT P\&O method.

This paper will be organized as follows. The modeling of the PV system exposed in Section 2. The proposed method explained in Section 3. The results from the implemented models and the MPPT capability of a stand-alone PV system presented and discussed in Section 4. The final conclusion addressed in Section 5.

\section{PV system modeling}

Solar cell is the device which absorbs the solar energy and converts it into electrical energy. These days, silicon PN junction cell is the most commonly used cell type. When solar radiation falls on this cell, photon creates an electron-hole pair. The output of this solar cell is very low, so many of these cells are connected in series or parallel. The number of cells connected in parallel increases the current and the number of cells connected in series increases the voltage. The circuit for the 5 parameter model given in [17] is shown in Fig. 1.

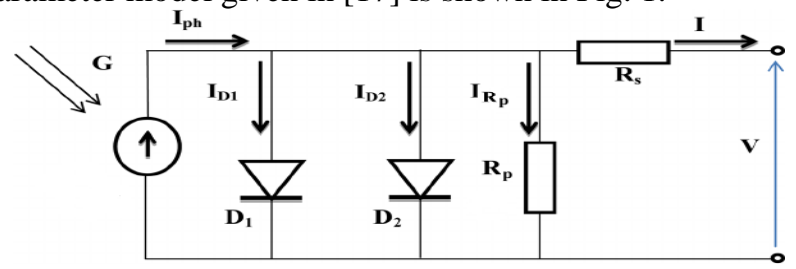

Fig. 1. Two diodes cell model.

The PV panel current is given by equation (1). This is known as double exponential model, which presents the best compromise between simplicity and accuracy [4].

$$
I=I_{p h}-I_{s 1}\left[e^{\frac{q\left(V+I . R_{s}\right)}{n_{1} k T}}-1\right]-I_{s 2}\left[e^{\frac{q\left(V+I . R_{s}\right)}{n_{2} k T}}-1\right]-\frac{V+I R_{s}}{R_{P}}
$$

$I_{s 1}$ and $I_{s 2}$ are the saturation currents of the diodes, $n_{1}$ and $\mathrm{n}_{2}$ are purity factors of the diodes, $\mathrm{R}_{\mathrm{s}}$ and $\mathrm{R}_{\mathrm{p}}$ are respectively the series resistance and the parallel resistance, $\mathrm{T}$ absolute temperature in Kelvin. The equation also contains the elementary charge constant $\mathrm{q}$ $\left(1,602 \cdot 10^{-19} \mathrm{C}\right)$ and the Boltzmann constant $\mathrm{k}\left(1,380.10^{-}\right.$ $\left.{ }^{29} \mathrm{j} / \mathrm{k}\right) . \quad \mathrm{I}_{\mathrm{ph}}$ The generated photocurrent given in equation(2).

\footnotetext{
* Corresponding author: ghedhabnabila1@ hotmail.fr
} 


$$
I_{p h}=\frac{G}{1000}\left[I_{s h}+k_{c}\left(T-T_{r e f}\right)\right]
$$

With, G solar irradiation in $\left(\mathrm{W} / \mathrm{m}^{2}\right), \mathrm{I}_{\mathrm{sh}}$ the $\mathrm{PV}$ cell short circuit current at reference temperature, $\mathrm{k}_{\mathrm{c}}$ the temperature coefficient of the short circuit current and $\mathrm{T}_{\text {ref }}$ the PV cell reference temperature.

The association of several PV cells in series-parallel gives rise to a photovoltaic generator, which has a current-voltage (I-V) characteristics non linear with an operating point (MPP) see Fig. 2. The maximum power transfer happens if the internal resistance of the system is equal to the load resistance. This can be achieved by inserting a DC-DC converter between the load and the PV system; in this study a boost converter is used to increase the output voltage as required by the battery.

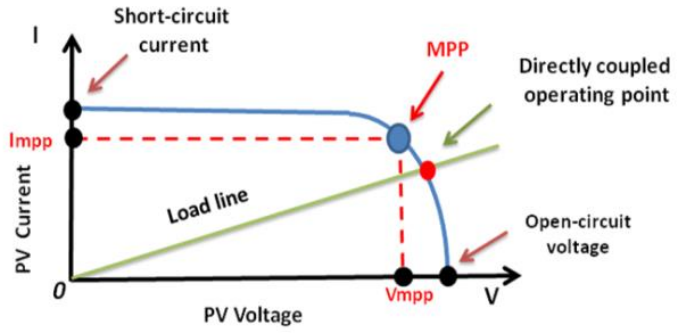

Fig. 2. I-V characteristics of PV system

The main inconvenient of PV systems is that the extracted power depends on weather conditions like ambient temperature and irradiation levels. This is why the maximum power has to be tracked continually to operate the PV panels at MPP at varying conditions. In the $\mathrm{P} \& \mathrm{O}$ method, the output power $\mathrm{P}(\mathrm{n})$ of the array is calculated every cycle and is compared to its previous value $\mathrm{P}(\mathrm{n}-1)$. If the perturbation $\mathrm{C}$ (either positive or negative) in the duty cycle (D) of the DC-DC converter $\mathrm{D}(\mathrm{n})=\mathrm{D}(\mathrm{n}-1) \pm \mathrm{C}$ increases the power output, the duty cycle is modified in the same direction. If the power output decreases, then it is altered to the opposite direction [5-6]. The flowchart of the MPPT P\&O is described in Fig. 3 and the global circuit diagram of the system adopted is shown in Fig. 4.

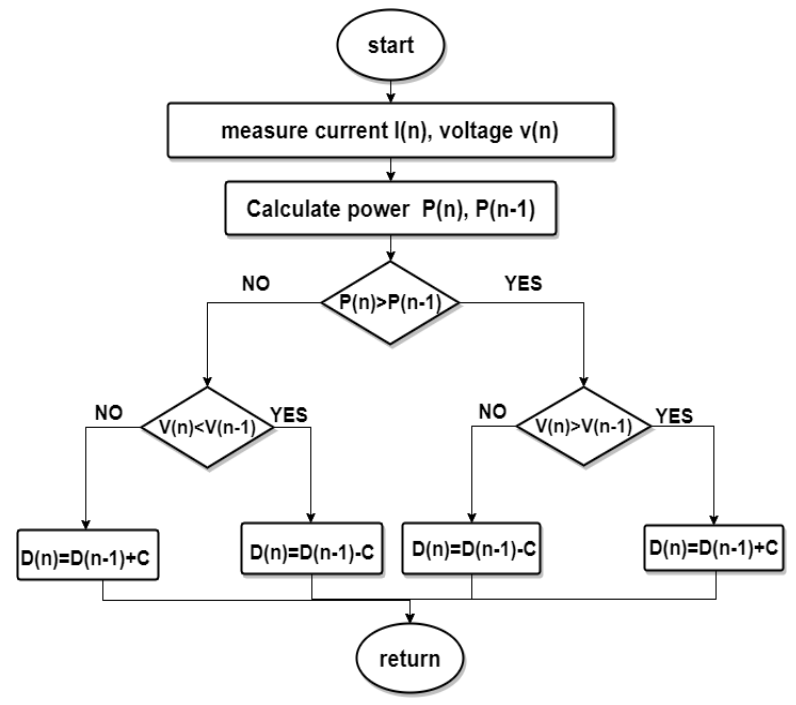

Fig. 3. Flowchart of the $\mathrm{P} \& \mathrm{O}$ algorithm

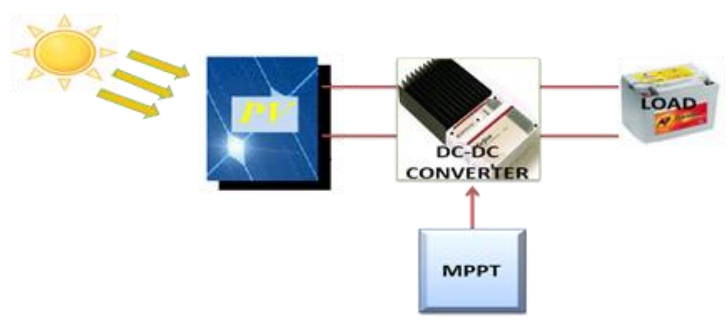

Fig.4. Bloc diagram of an optimized photovoltaic generator using MPPT controller.

\section{Artificial Neural Network based MPPT for PV systems}

The advance in artificial intelligence during this century, drives the scientists toward Artificial Neural Network ANNs, which are inspired by the functioning of the brain and its ability to learn things over time. The idea behind this process is to collect a set of inputs and their corresponding output, then teach the ANN how to process them like black box, at that time it must be able to predict a desired output from a different set of inputs which didn't contribute during the learning phase. This ability of prediction inspired the use of ANNs in different field and suggest solutions to many problems, what inspired a significant number of researcher to work on ANN with MPPT techniques [18-19].

\subsection{Training of a Neural Networks}

The training data are the most important parameters to the success of every ANN, in this study the input data were collected from real weather conditions from a given site in the south of Algeria, hence irradiance $G$ and temperature $\mathrm{T}$ were collected for 9 years, then selected data set from one typical year were used as inputs of the ANN, simulation of the PV system in Matlab/Simulink by means of the MPPT P\&O method helped to supply the target data ,duty cycle D of the boost converter.

\subsection{Description and architecture of the proposed Neural Network Controller}

The neural network is trained in the offline mode using the graphical user interface nftool from Matlab. The number of data set to use is 365 , they are divided into three parts $75 \%$ for training, $15 \%$ for test and $15 \%$ for validation. The training is done using LevenbergMarquardt algorithm [7]. A structure with 10 neurons in the hidden layer is selected. The architecture of the ANN controller is shown in Fig.5, inputs of the ANN controller are the temperature $\mathrm{T}$ and irradiance $\mathrm{G}$, while the output is the duty cycle D

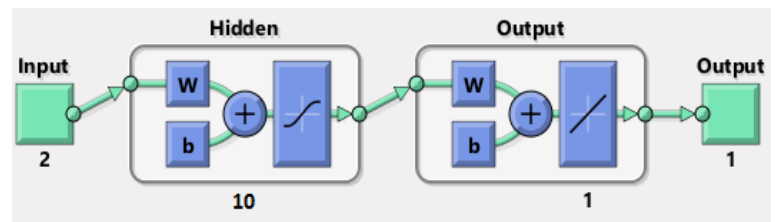

Fig. 5. The proposed neural network architecture in Matlab. 


\subsection{Modeling and Simulation of PV System with ANN controller}

After the training of the ANN controller in Matlab the obtained results are exported to Simulink. The Unmasked bloc is shown in Fig. 6. The diagram of the PV generator used in the simulation is shown in Fig. 7.

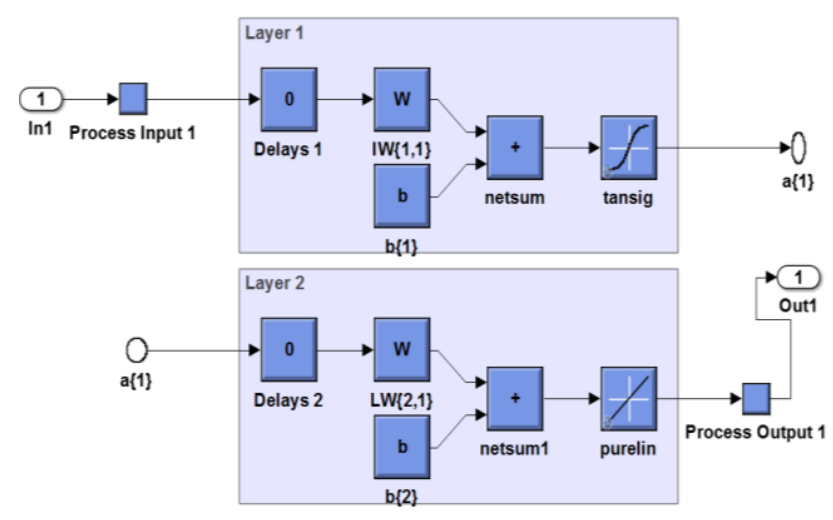

Fig. 6. Unmasked ANN controller subsystem

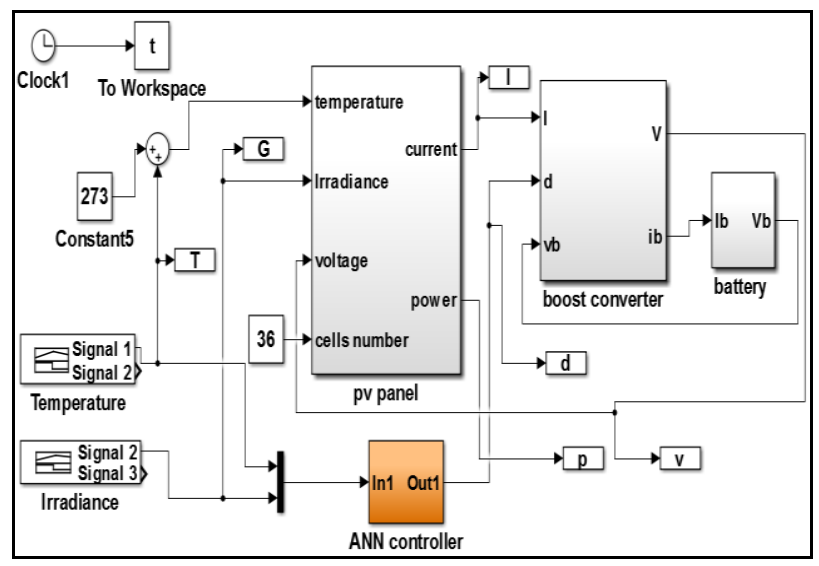

Fig.7. Matlab/Simulink Block diagram of the PV system with the proposed ANN controller

Table 1 shows a random comparison between some trained and simulated data sets. This will illustrate the capacity of generalization of the ANN controller, with only two inputs it can predict the value of the duty cycle, without needing the PV system parameters.

Table 1. comparison between trained and simulated value of the duty cycle.

\begin{tabular}{|c|c|c|c|c|}
\hline $\mathbf{G}$ & \multirow{2}{*}{$\mathbf{W} / \mathbf{m} 2)$} & \multicolumn{3}{|c|}{ Duty cycle } \\
\cline { 3 - 5 } & $\mathbf{T}\left({ }^{\circ} \mathbf{C}\right)$ & Trained value & $\begin{array}{c}\text { Simulated } \\
\text { value }\end{array}$ & $\begin{array}{c}\text { Error } \\
\text { percentage }\end{array}$ \\
\hline 1000 & 25 & 0,638 & 0.623 & 2.35 \\
\hline 800 & 23 & 0.556 & 0.542 & 2.52 \\
\hline 700 & 26 & 0,526 & 0.528 & 0.38 \\
\hline 600 & 23 & 0,484 & 0.498 & 2.89 \\
\hline 400 & 14 & 0.388 & 0.421 & 8.5 \\
\hline
\end{tabular}

\section{Simulation and study}

In order to demonstrate the performance of the proposed ANN controller a comparison between the proposed method and the classical P\&O method is mandatory. Simulation in Matlab/Simulink of both PV systems are done under Standard Test Conditions STC $\left(T=25^{\circ} \mathrm{C}\right.$, $\mathrm{G}=1000 \mathrm{~W} / \mathrm{m}^{2}$, AM 1.5), results are shown in Fig.8.

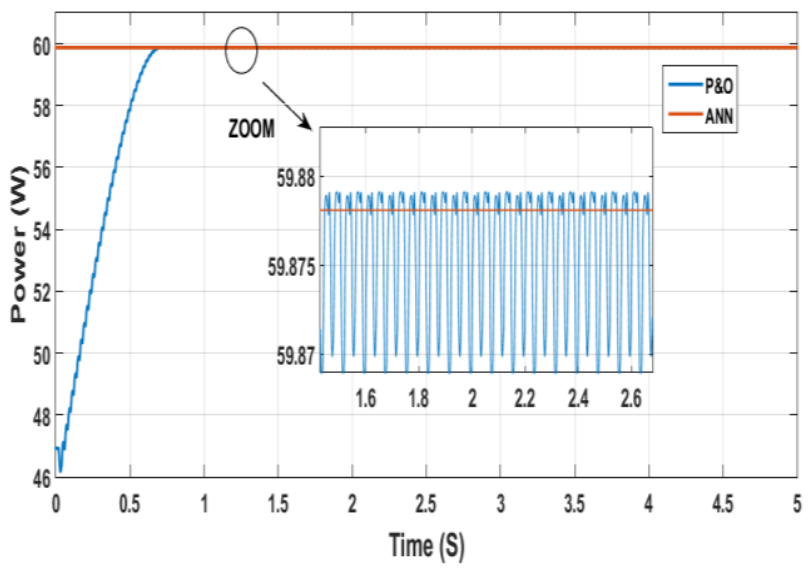

Fig. 8. MPPT simulation of the P\&O and ANN methods under STC.

According to the obtained result, it's shown that the ANN controller presents a better performance than the MPPT P\&O one. The proposed MPPT ANN method tracks the maximum power $\left(\mathrm{P}_{\max }=60 \mathrm{w}\right.$ at $\left.1000\left(\mathrm{w} / \mathrm{m}^{2}\right)\right)$ with 0 s response time and zero oscillations around the MPP, while the classical method tracks the same maximum power within response time equals $(t=0.7 \mathrm{~s})$ with a significant oscillation around the MPP.

To confirm the ability of our controller under fast variation of weather conditions simulations using different scenarios are done as follows:

- The temperature is kept constant $\left(\mathrm{T}=25{ }^{\circ} \mathrm{C}\right)$ and the solar irradiance $G$ varies from $1000\left(\mathrm{w} / \mathrm{m}^{2}\right)$ to 700 $\left(\mathrm{w} / \mathrm{m}^{2}\right)$ then up to $900\left(\mathrm{w} / \mathrm{m}^{2}\right)$, as shown in Fig. 9.

- A random variation of $\mathrm{G}$ and $\mathrm{T}$ at the same moment is proposed and shown in Fig. 10.

The results of both systems are shown in the same figure, to deduce which one is giving best performance.

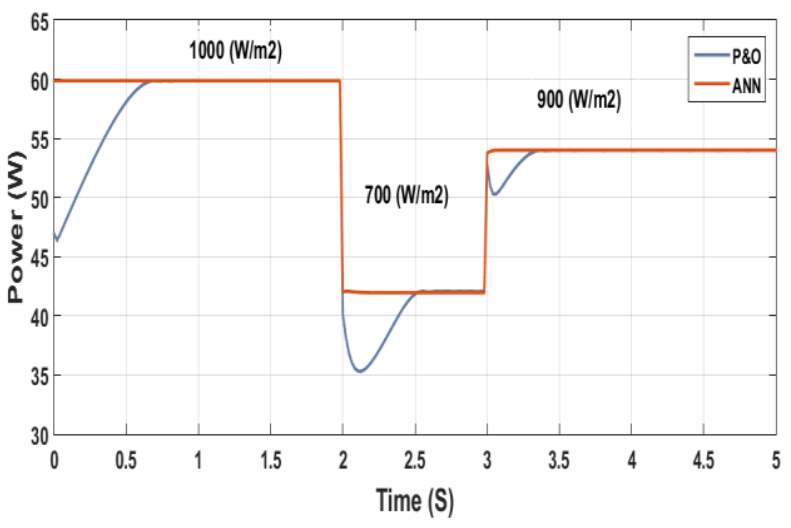

Fig. 9. PV output power case of irradiance change 


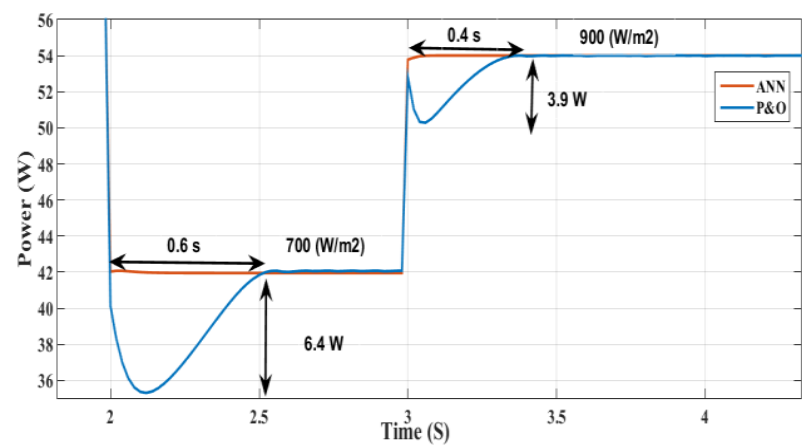

Fig. 10. Zoom on overshoot case of irradiance increase and decrease

Again, the above results (Fig.9 and Fig. 10) confirm the quality of the output power in case of suddenly decreasing or increasing irradiation with ANN controller in terms of response time and overshoot. While $\mathrm{P} \& \mathrm{O}$ output power presents oscillations around the MPP, what generate power losses illustrated by overshoot power $(0.7 \mathrm{~s}, 6.4 \mathrm{w})$ in case of sudden decrease of irradiance and $(0.4 \mathrm{~s}, 3.9 \mathrm{w})$ in case of sudden increase of irradiance, that can be avoided using the ANN controller, which shows significant stability.

In the following simulation the PV system will be evaluated under a random variation of atmospheric condition, as shown in Fig. 11. The resulted duty cycle and output power are shown in Fig. 12 and Fig. 13 respectively.
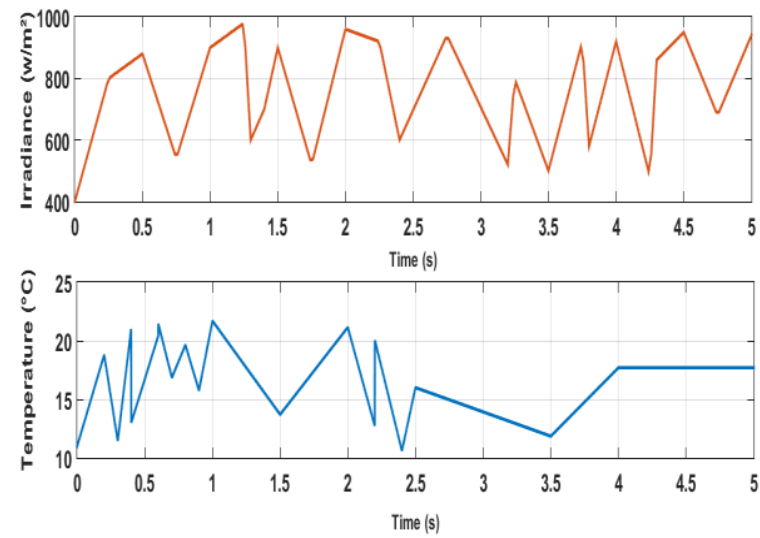

Fig. 11. Random variation of irradiance and temperature.

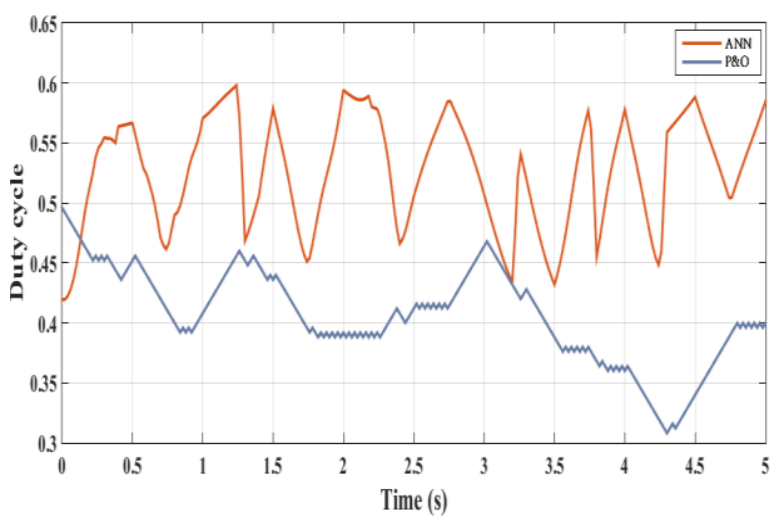

Fig. 12. Duty cycle case of random variation of irradiance and temperature

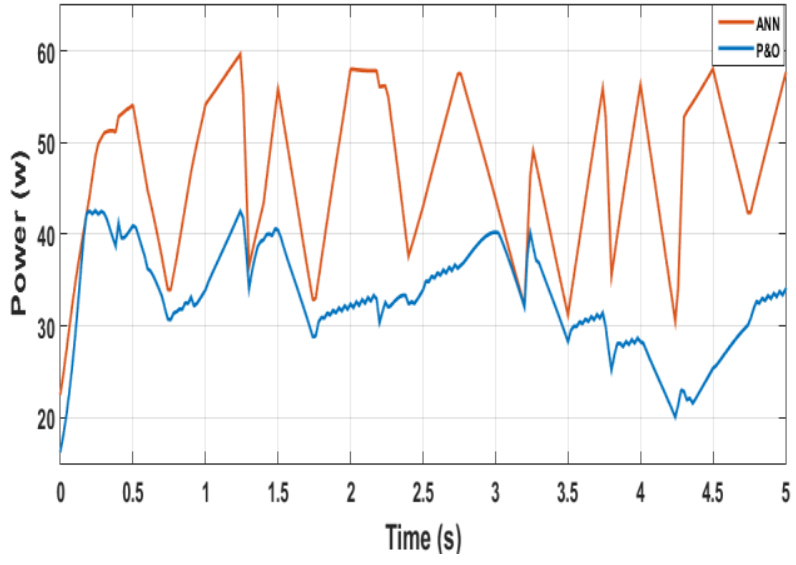

Fig. 13. PV output power case of random variation of irradiance and temperature.

For a very fast variation of irradiance, the duty cycle from $\mathrm{P} \& \mathrm{O}$ algorithm fail to track the MPP, the tracking is almost done in the wrong direction, whereas the ANN duty cycle confirm again it performance and track the irradiance levels perfectly, as consequence, the error variation in the PV output power illustrated in Fig. 14 from both methods demonstrates how the ANN technique added, approximately, $20 \%$ of the power delivered from the PV panel compared to the conventional method MPPT P\&O; this accuracy is due to the very fast response time and the perfect training of the ANN controller.

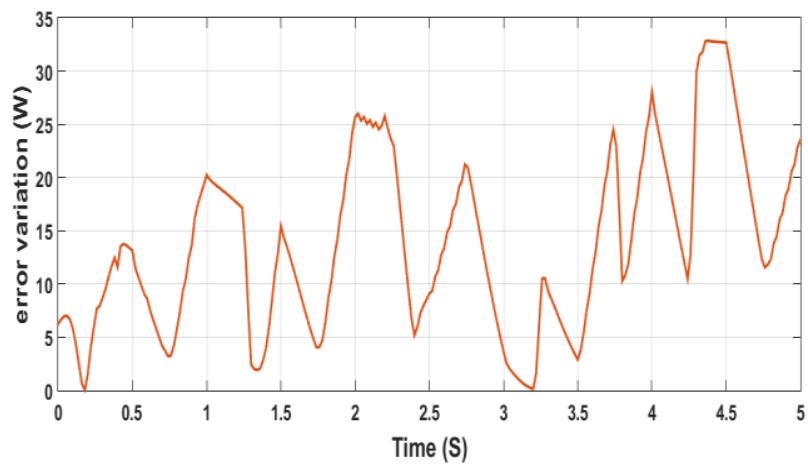

Fig. 14. Power error variation case of random variation of irradiance and temperature

\section{Conclusion}

This paper presents the high performances of the ANN based MPPT algorithm designed to the boost converter supplied PV systems. The proposed method response time is very fast with zero oscillation during the steady state. Furthermore, the proposed ANN increased the PV output power by approximately $20 \%$. The results obtained gives accurate predictions over a wide variety of operating modes, especially for a very fast change of weather conditions. The proposed method can also be a useful tool for PV system designers for the optimal configuration of a PV system. Further work is being conducted on the overall system design and experimental implementation. 


\section{References}

1. A. Stambouli Boudghene, Z. Khiat, S. Flazi, Y. Kitamura, Renew Sust Energ Rev 16, 4445-4460 (2012)

2. T Esaram, P L. Chapman, IEEE Transactions on Energy Conversion EC, 22(2), 439 (2007)

3. A R. Reisi, M. Moradi, S. Jamasb, Renew Sust Energ Rev, 19, 433-443 (2013)

4. D P. Hohm, M E. Ropp. Progress in photovoltaic research and application, 11, 47-62 (2003)

5. N. Femia, G. Petrone, G. Spagnuolo, M. Vitelli, IEEE trans pow electro, 20(4), (2005)

6. M A. Elgendy, B. Zahawi, D J. Atkinson, IEEE Trans Sust Energ, 3(1), 21-33(2012).

7. A. Loukriz, M. Hadadi, S. Messalti, ISA trans, 62, 30-38(2016)

8. A .Safari, S. Mekhilef. IEEE Trans Ind Electron, 58, 1154-1161(2011)

9. T. Hiyama, K. Kitabayashi, IEEE Trans Energy Conver, 12, 241-247(1997)

10. M C.Di Piazza, M.Pucci, G.Vitale, Sust Energ Tech, and Assessments 2, 19-30 (2013)

11. S. Messalti , A.Harrag, A.Loukriz, Renew and sust energ rev, 68, 221-233 (2017)

12. K H. Hussein, G. Zhao, IEE Proc- Gener. Transm. Distrib, 142 (1) , 59-64 (1995)

13. N Ghedhab, F Youcefettoumi, Int. J. Environ. Sci. Technol, 7(9), 642-645 (2016)

14. C. Larbes, S M A. Cheikh, T. Obeidi, A. Zerguerras, Renew Energ, 34(10), 2093-2100 (2009)

15. B. Bendib, F. Krim, H. Belmili, M F. Almi, S. Bolouma, IEEE 23rd International Symposium on Industrial Electronics (ISIE), Istanbul, 404-409 (2014)

16. A A. Kulaksiz and R. Akkaya, Solar Energy, 86(9), 2366-2375 (2012)

17. J A. Gow, C D. Manning, IEEE Proceedings on Electric Power Applications, 146(2), 193-200 (1999)

18. L M. Elobaid, A K. Abdelsalam, E E. Zakzouk, IET Renew Power Gener, 9(8), 1043-1063 ( 2015)

19. S. Messalti, A. Harrag, A Loukriz, Renew Sust Energ Rev, 68, 221-233(2017) 